\title{
OPTIMIZATION OF PROCESS PARAMETERS FOR MACHINING
}

\section{OF ALUMINUM 6061-O ALLOY ON LATHE}

\section{AND DRILLING MACHINE}

\author{
A. SURESH ${ }^{1} \&$ G. DIWAKAR ${ }^{2}$ \\ ${ }^{I}$ Research Scholar, Department of Mechanical Engineering, Koneru Lakshmaiah Education \\ Foundation (Deemed to be University), Vaddeshwaram, Andhra Pradesh, India \\ ${ }^{2}$ Professor, Department of Mechanical Engineering, Koneru Lakshmaiah Education \\ Foundation (Deemed to be University), Vaddeshwaram, Andhra Pradesh, India
}

The assessment of the process capability is an important aspect for any machine, may it works for commercial or any other purposes. As this is the motto of the project, the machines in the mechanical laboratories were taken into consideration. In these laboratories, mainly the lathe, drilling and milling machines were taken into consideration for the assessment of the process capability. These machines were considered for the process capability of the turning and drilling on these machines with aluminum 6061-O alloy. Almost 90 specimens were taken into consideration and, their process capability is determined, then along with that the applicability of the machines were also found. This has helped in assessing the process capability of the lathe machines with the respective specimens and their applicability is deeply analyzed.
\end{abstract}

KEYWORDS: Process Capability, Lathe \& Drilling

Received: Jul 18, 2018; Accepted: Aug 07, 2018; Published: Aug 25, 2018; Paper Id.: IJMPERDOCT201811

\section{INTRODUCTION}

Process capability assessment is one of the important parameters to be considered for efficient and effective utilization of the machines. The process capability index will make sense the ability and capability of the machine, as to what extent it can discharge its intended functions. Even though the manufacturing and making of machine is unique, in reality, the machine functioning will alter, because of the difference in the follow up of production planning and its control. Hence, it is the customary responsibility for an engineer to assess the degree of accuracy for utilization of the machine. As a part of this, lathe and drilling machines were considered to perform the turning and drilling operation on aluminum 6061-O alloy work pieces. The process of turning and drilling is repeated over a 30 work pieces for each operation and, the analysis is made for the finding of control limits. Thereby, the control charts were made to know the machine capability. The complete work has been described by the following methodology. 


\section{METHODOLOGY}

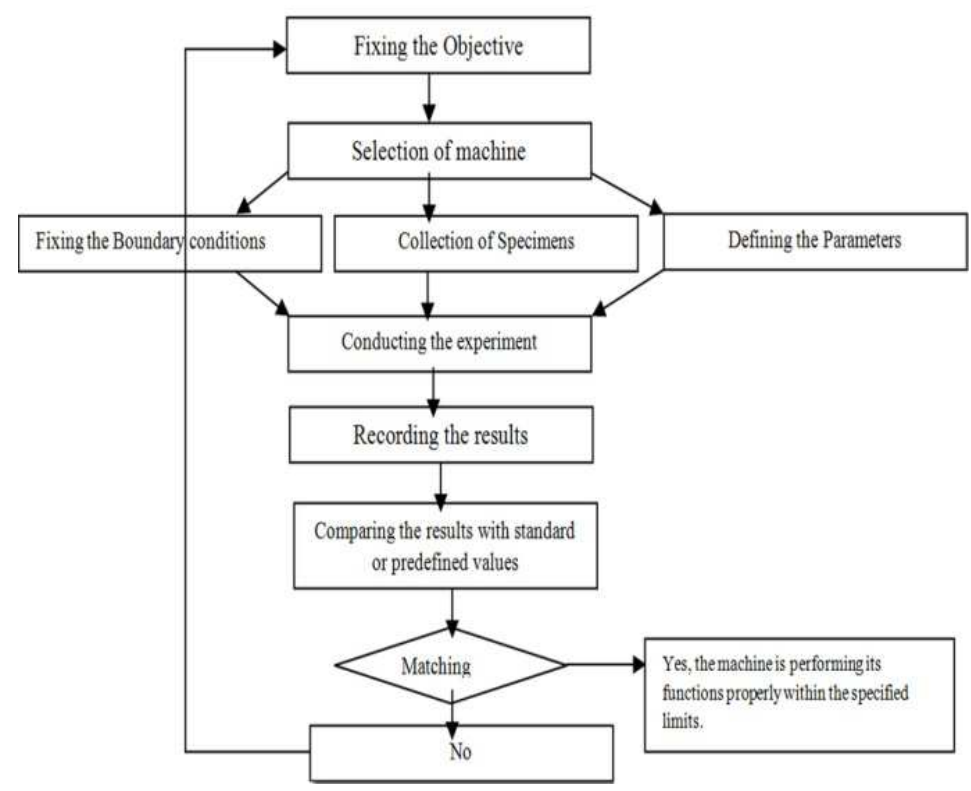

Figure 1

The above flow chart describes the method of carrying out the research. At first, some assumptions were made for the work to be done. They are:

- The time taken for machining of all the work pieces is same, as that is a constant.

- The chips that are produced were continuous and it doesn't create any chatter on the surface of the work piece.

- The cutting tool does not get any wear, and it doesn't create any unevenness on the or inside the surface of the work piece.

- Machine is free from vibrations and is fixed properly. That means machine vibrations due to rotating parts do not have any influence on the work piece. For plotting the control charts, the following formula is used.

For plotting X - CHART

Upper Control Limit UCL $=\mathrm{X}+\mathrm{A} 2 \mathrm{R}$

Lower Control Limit LCL $=\mathrm{X}-\mathrm{A} 2 \mathrm{R}$

For plotting $\mathrm{R}-\mathrm{CHART}$

Center Line $(\mathrm{CL})=\mathrm{R}$

Upper Control Limit $(\mathrm{UCL})=\mathrm{RD}_{4}$

Lower Control Limit $(\mathrm{LCL})=\mathrm{RD}_{3}$

$R_{3}$ is the mean of the ranges in the sample process. $A_{2}, D_{4}$ and $D_{3}$ are variables in the appropriate statistical (SQC) table. 


\section{ANALYSIS}

\section{Case 1: Lathe Machine}

Table shows the data obtained for three attempt of the turning process at various speed and feed rate of the operation. The work piece is of $300 \mathrm{~mm}$ length and the initial diameter is $45 \mathrm{~mm}$. The number of work pieces is 90 .

Table 1

\begin{tabular}{|c|c|c|c|c|c|c|}
\hline $\begin{array}{c}\text { Sub } \\
\text { Group } \\
\text { Number }\end{array}$ & $\begin{array}{c}\text { Speed } \\
(\mathrm{N}) \\
\text { RPM }\end{array}$ & $\begin{array}{l}\text { Feed/ } \\
\text { rev. } \\
\text { (f) }\end{array}$ & $\begin{array}{c}\text { Dia } \\
\text { (d1) } \mathrm{mm}\end{array}$ & $\begin{array}{c}\text { Dia. } \\
\text { (d2) } \mathrm{mm}\end{array}$ & $\begin{array}{l}\text { Dia. } \\
\text { (d3) } \\
\text { mm } \\
\end{array}$ & $\begin{array}{l}\text { Average } \\
\text { dia. } \mathrm{mm}\end{array}$ \\
\hline 1 & 500 & 0.5 & 39.963 & 39.962 & 39.962 & 39.962 \\
\hline 2 & 500 & 0.5 & 39.961 & 39.964 & 39.964 & 39.963 \\
\hline 3 & 500 & 0.5 & 39.965 & 39.955 & 39.955 & 39.958 \\
\hline 4 & 500 & 0.5 & 39.960 & 39.955 & 39.960 & 39.959 \\
\hline 5 & 500 & 0.5 & 39.955 & 39.955 & 39.955 & 39.955 \\
\hline 6 & 500 & 0.5 & 39.960 & 39.960 & 39.960 & 39.960 \\
\hline 7 & 500 & 0.5 & 39.965 & 39.965 & 39.965 & 39.965 \\
\hline 8 & 500 & 0.5 & 39.955 & 39.960 & 39.960 & 39.958 \\
\hline 9 & 500 & 0.5 & 39.960 & 39.965 & 39.965 & 39.963 \\
\hline 10 & 500 & 0.5 & 39.955 & 39.955 & 39.965 & 39.958 \\
\hline 11 & 500 & 0.5 & 39.965 & 39.955 & 39.955 & 39.955 \\
\hline 12 & 500 & 0.5 & 39.960 & 39.960 & 39.960 & 39.960 \\
\hline 13 & 500 & 0.5 & 39.955 & 39.965 & 39.960 & 39.960 \\
\hline 14 & 500 & 0.5 & 39.965 & 39.955 & 39.965 & 39.961 \\
\hline 15 & 500 & 0.5 & 39.955 & 39.960 & 39.960 & 39.958 \\
\hline 16 & 500 & 0.5 & 39.962 & 39.950 & 39.959 & 39.959 \\
\hline 17 & 500 & 0.5 & 39.957 & 39.959 & 39.960 & 39.958 \\
\hline 18 & 500 & 0.5 & 39.959 & 39.962 & 39.961 & 39.960 \\
\hline 19 & 500 & 0.5 & 39.959 & 39.960 & $39.960-$ & 39.960 \\
\hline 20 & 500 & 0.5 & 39.965 & 39.964 & 39.965 & 39.964 \\
\hline 21 & 500 & 0.5 & 39.963 & 39.962 & 39.962 & 39.962 \\
\hline 22 & 500 & 0.5 & 39.960 & 39.962 & 39.960 & 39.960 \\
\hline 23 & 500 & 0.5 & 39.955 & 39.955 & 39.955 & 39.955 \\
\hline 24 & 500 & 0.5 & 39.955 & 39.955 & 39.955 & 39.955 \\
\hline 25 & 500 & 0.5 & 39.962 & 39.961 & 39.962 & 39.962 \\
\hline 26 & 500 & 0.5 & 39.959 & 39.961 & 39.959 & 39.960 \\
\hline 27 & 500 & 0.5 & 39.960 & 39.961 & 39.958 & 39.960 \\
\hline 28 & 500 & 0.5 & 39.965 & 39.955 & 39.955 & 39.958 \\
\hline 29 & 500 & 0.5 & 39.960 & 39.965 & 39.965 & 39.963 \\
\hline 30 & 500 & 0.5 & 39.962 & 39.961 & 39.963 & 39.962 \\
\hline
\end{tabular}

Likewise, the above table, by varying the speed $(400 \mathrm{rpm} \& 300 \mathrm{rpm})$ and feed $(0.35 \& 0.25$ per rev $)$, different diameters was found. As such, a total of 90 readings were receded. For accuracy, each reading is taken at three places around the circumference. And, the average is taken as the standard value.

Table 2

\begin{tabular}{|l|c|c|c|c|}
\hline \multicolumn{4}{|c|}{ Control Limit Values or Turned Shaft Data } \\
\hline \multirow{2}{*}{} & \multirow{2}{*}{ Center Line } & Control Limits & \multirow{2}{*}{ Standard Deviation } \\
\cline { 3 - 4 } & & UCL & LCL & \\
\hline X bar chart & 39.96 & 39.966 & 39.955 & \multirow{2}{*}{0.003} \\
\hline R chart & 0.006 & 0.015 & 0 & \\
\hline
\end{tabular}




\section{Case 2: Drilling Machine}

Table shows the data obtained for three attempt of the turning process at various speed and feed rate of the operation. The work piece is of $150 \mathrm{~mm}$ length and the initial diameter, $207 \mathrm{~mm}$. The number of work pieces is 90 .

Table 3

\begin{tabular}{|c|c|c|c|c|c|c|}
\hline ole & $\begin{array}{c}\text { D1 } \\
\text { mm }\end{array}$ & $\begin{array}{c}\text { D2 } \\
\text { mm }\end{array}$ & $\begin{array}{c}\text { D3 } \\
\text { mm }\end{array}$ & $\begin{array}{c}\text { Average } \\
\mathrm{mm}\end{array}$ & Range & $\begin{array}{c}\text { Mean } \\
\text { mm }\end{array}$ \\
\hline 1 & 205.007 & 205.006 & 205.008 & 205.007 & .025 & 204.999 \\
\hline 2 & 05.006 & 205.005 & 205.007 & 205.006 & 0.025 & 204.999 \\
\hline 3 & 05.982 & 205.981 & 205.983 & 205.982 & 0.025 & 204.999 \\
\hline 4 & 05.005 & 205.004 & 205.006 & 205.005 & 0.025 & 204.999 \\
\hline 5 & 05.996 & 205.995 & 205.997 & 205.996 & 0.025 & 204.999 \\
\hline 6 & 205.995 & 205.994 & 205.996 & 205.995 & 0.026 & 205.008 \\
\hline 7 & 05.000 & 205.001 & 205.001 & 00 & & 205.008 \\
\hline 8 & 205.010 & 205.009 & 205.011 & 205.010 & 0.026 & 205.008 \\
\hline 9 & 205.021 & 205.020 & 205.022 & & & \\
\hline 10 & 205.016 & 205.015 & 205.017 & 016 & 26 & 205.008 \\
\hline 11 & 05.994 & 205.0993 & 205.995 & & & 204.997 \\
\hline 12 & & & & & & \\
\hline 13 & 05.990 & 205.098 & 205.991 & 990 & & 204.997 \\
\hline 4 & & & & & & \\
\hline 15 & 05.985 & 205.984 & 205.986 & 85 & 28 & 204.997 \\
\hline 16 & & & & & & \\
\hline 17 & 205.016 & 205.015 & 205.017 & 16 & 46 & 205.007 \\
\hline 18 & 205.037 & 205.036 & 205.038 & 37 & 46 & 205.007 \\
\hline 19 & 205.994 & 205.993 & 205.995 & 994 & 0.046 & 205.007 \\
\hline 20 & 205.991 & 205.990 & 205.992 & 991 & 0.046 & 205.007 \\
\hline 21 & 205.019 & 205.018 & 205.020 & 019 & 0.039 & 205.006 \\
\hline 22 & 205.994 & 205.993 & 205.995 & 994 & 39 & 205.006 \\
\hline 23 & 205.022 & 205.021 & 205.023 & 205.022 & 0.039 & 205.006 \\
\hline 24 & 205.983 & 205.982 & 205.984 & 983 & 0.039 & 205.006 \\
\hline 25 & 205.011 & 205.010 & 205.012 & & & 205.006 \\
\hline 26 & 205.993 & 205.992 & 205.994 & 205.993 & 0.053 & 205.010 \\
\hline 27 & 205.038 & 205.037 & 205.039 & 205.038 & & 205.010 \\
\hline 28 & 205.028 & 205.027 & 205.029 & 205.028 & 0.053 & 205.010 \\
\hline 29 & 205.007 & 205.006 & 205.008 & 205.007 & & 205.010 \\
\hline 30 & 205.985 & 205.984 & 205.986 & 205.985 & 0.053 & 205.010 \\
\hline
\end{tabular}

Control limits for $\mathrm{x}$ bar chart

$$
\begin{aligned}
& \mathrm{UCL}=\mathrm{X}_{2}+\mathrm{A}_{2} \mathrm{R}=205.001+0.577 * 0.033=205.020 \\
& \mathrm{LCL}=\mathrm{X}_{2}-\mathrm{A}_{2} \mathrm{R}=205.001-0.577 * 0.033=204.982
\end{aligned}
$$

Control limits for $\mathrm{R}$ chart

$$
\begin{aligned}
& \mathrm{UCL}=\mathrm{D}_{4} \mathrm{R}=2.114 * 0.033=0.070 \\
& \mathrm{LCL}=\mathrm{D}_{3} \mathrm{R}=0.00 * 0.033=0
\end{aligned}
$$

From the table of standard values for control charts $n=5, A_{2}=0.577, D_{2}=2.326, D_{4}=2.114$ 


\section{RESULTS}

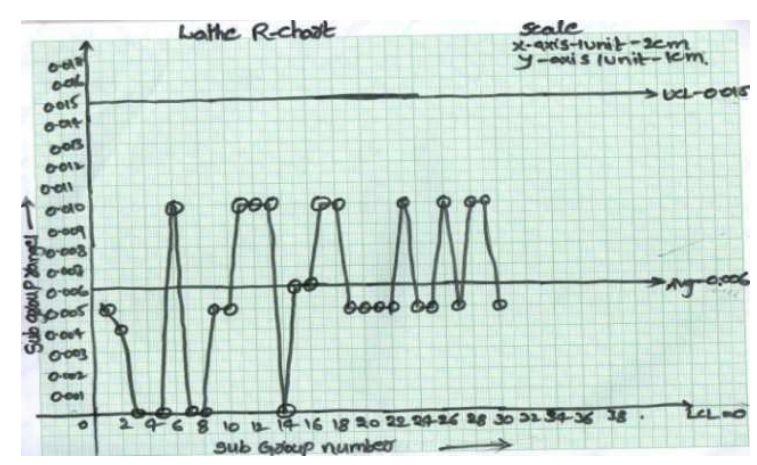

Figure 2

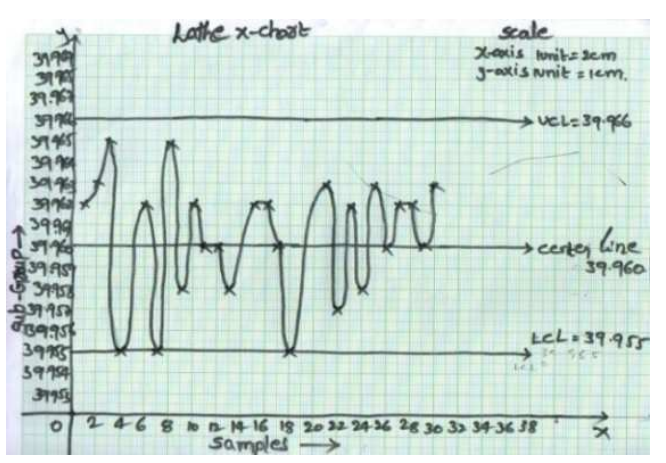

Figure 3

By observing the above graphs, it is a clear indication that the machine is producing the elements with the statistical limits, and hence it can be concluded that the machine can be used for the engineering applications.

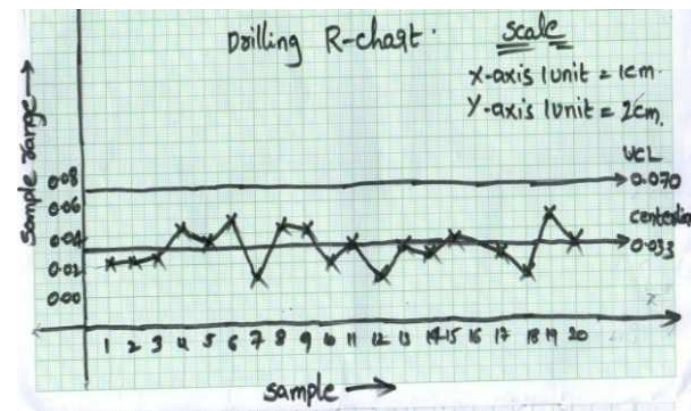

Figure 4: X Bar Chart for Drilling Machine

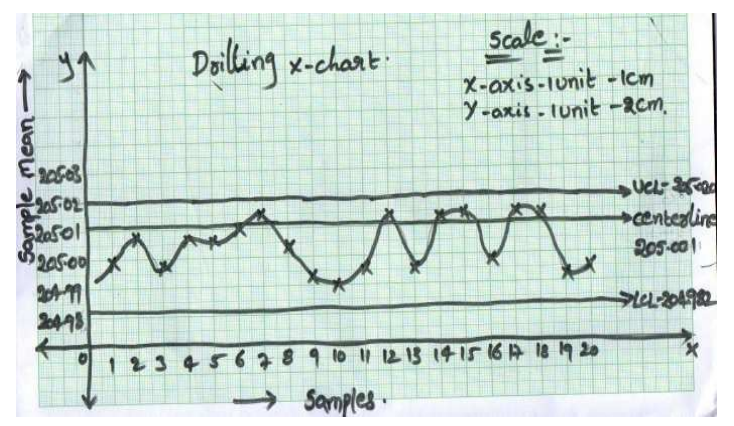

Figure 5: R Bar Chart for Drilling Machine

It has been observed that all the plotted sample range and mean values are within the control limits on both RChart as well as $\mathrm{X}$ bar chart, and there are no indications of Trend, shift, run and clustering.

Hence, it is concluded that the process is under statistical control and operating, under the influence of only chance as causes of variation. i.e. the process is stable over time.

\section{CONCLUSIONS}

The process capability and its assessment for the lathe machine are done, and the machine is capable for performing that particular operation. All the specimen values for these operation lie within the control limits, that is Lower control limit $=39.995 \mathrm{~mm}$ and the Upper control limit is $=39.966 \mathrm{~mm}$. The central limit for this operation is $=39.960 \mathrm{~mm}$. In addition to this, the $\mathrm{R}$ chart also has been drawn for the same operation. The Upper and Lower control limits for this operation would be $0.015 \mathrm{~mm}$ and $0 \mathrm{~mm}$ respectively, and the central limit value is $=0.006 \mathrm{~mm}$. This graph also has yielded that the process is within the limits.

Likewise, the Drilling operation also has been considered for the capability assessment. As part of that, the Upper and Lower control limits were $205.020 \mathrm{~mm}$ and the Upper Control limit value is $24.982 \mathrm{~mm}$ respectively, and the central limit is $205.001 \mathrm{~mm}$. All the specimen values have come within the control limits, hence the process is capable. Then, the $\mathrm{R}$ chart also is drawn for the same operation, and it has yielded the Upper and Lower control limits as 0.070mm and 0mm, respectively and, the central limit is $0.033 \mathrm{~mm}$. It has also shown that, the values for the operation are within the control limit. 


\section{REFERENCES}

1. Process Capability Analysis as a Means of Decision Making in Manufacturing Company, Adeoye Akeem. O., Adedoyin, Salami. I., Alawaye Anthonia. I., IJARCST, ISSN: 2347-8446

2. Process Capability Analysis by Using Statistical Process Control of Rice Polished Cylinder Turning Practice, S. Bangphan, P. Bangphan, T. Boonkang IJMAIMME Vol 8, No 12, 2014

3. Venkatesh, B., \& Sikarwar, R. S. Drilling Of Carbon Fibre Reinforced Polymer Materials-A Review.

4. The process capability analysis - A tool for process performance measures and metrics - A case study, Yerrisamy wooluru, Swamy D. R., P. Nagesh, IJQR8(3), ISSN: 1800-6450

5. Process Capability Analysis of a Centre Lathe Turning Process Andrew A. Erameh, Nurudeen A. Raji, Rasheed O. Durojaye , Abiodun A. Yussouff 